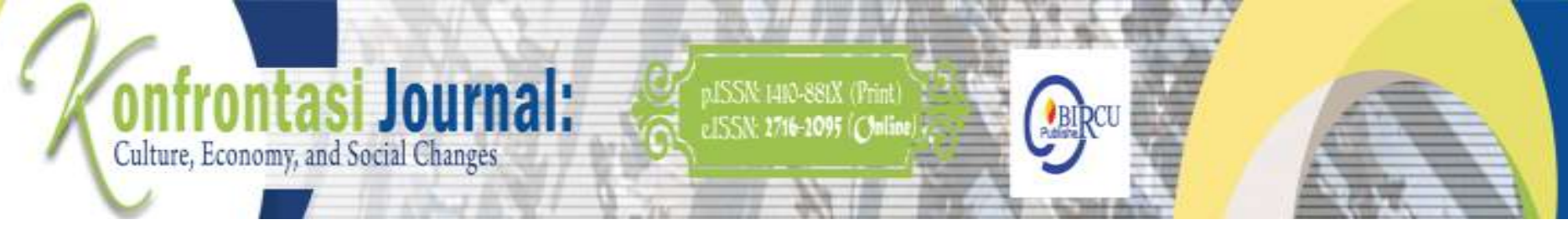

\title{
Digital Identity
}

\author{
Majeed Mohamed Fareed Majeed ${ }^{1}$, Abdurahman Adisaputera ${ }^{2}$, Muhammad Ridwan ${ }^{3}$ \\ ${ }^{1}$ English Department, Institute of Philology, Taras Shevchenko National University of Kiev \\ ${ }^{2}$ Universitas Negeri Medan, Indonesia \\ ${ }^{3}$ Universitas Islam Negeri Sumatera Utara, Indonesia \\ Mohammedik.f.m.86@gmail.com,bukharyahmedal@gmail.com
}

\begin{abstract}
With the penetration and spread of the Internet in our daily life, issues related to our identity on the Internet and their potential impacts on our lives, whether positive or negative, have become very important. We, as individuals, interact with a number of websites and services on the Internet that require an account (username and password) to access. These sites range from simple news sites that limit the number of articles that you can read anonymously in a certain period of time, to financial services or healthcare sites or others. Similar services on the Internet require that you know with certainty that you are definitely "you" before granting you access to any private information. Of course, we want them to confirm our identity before allowing access to this type of very sensitive information, which can be used to inflict harm. Take us in different ways if you fall into the wrong hands. The presence in the virtual world has formed the digital identity, and this digital identity has different effects on the morals and habits of the users in this virtual world. Because of the existence of a digital identity, you may also be exposed to some type of privacy crime. In this case, we must study and adapt to create patterns of coexistence and resilience in the digital environment.
\end{abstract}

Keywords

digital identity, privacy, social network, violation; virtual world

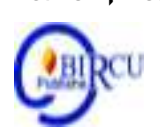

\section{Introduction}

The word identity stems from the Latin word idem, which means sameness. In the social sciences, the notion of identity has been widely used in different contexts and for distinct purposes. Identity, in these sciences, may refer to the instinctive perception of self or a badge enlightening group memberships (Holland, 2001; Norton, 2010). Additionally, Identity can "refer to an individual's own subjective sense of self, to personal classification 'markers' that appear as important, both to oneself and to others, and also to those markers that delineate group membership(s)". (Edwards, 2009, p.16).

The study of identity is, at heart, the study of how individuals and groups answer the "Who are you?" question (Vignoles, Schwartz, \& Luyckx, 2001, p. 289).

Conceptualizations of identity vary greatly within and across disciplines, so that the concept of identity often seems difficult to pin down. Identity has been defined as "unitary" or "multiple", "real" or "constructed", "stable" or "fluid", "personal" or "social", and in many other ways that often seem to contradict each other (Vignoles et al., 2011, pp. 289-290). 
Konfrontasi Journal: Culture, Economy and Social Changes, 7 (4) December 2020, 246-252

ISSN: 1410-881X (Print), 2716-2095 (Online)

Majeed Mohamed Fareed Majeed, Abdurahman Adisaputera, Muhammad Ridwan: Digital Identity DOI: https://doi.org/10.33258/konfrontasi2.v7i4.122

http://www.konfrontasi.net/index.php/konfrontasi2

Between real and virtual world there is an existing and renewed conflict, which is the struggle of identities, identity is a set of fixed, transformed and changing constituents, and these basic constituents are composed of the distinctive character of each individual entity from the other, but sometimes they may intersect in common with other people. These ingredients consist of (religion, culture, language, gender, land and history). Identity, like the artistic painting, is drawn by everyone from himself, based on his experiences and experiences that he builds from his interactions with the other. But in light of modern technology, this technology is based on compensating the true identity of the individual, and weaving his identities that are not related to spatial space and reduce the feeling of belonging to him. With the unlimited proliferation of technologies and the globalization of technology and information, virtual identities have emerged on the ground.

Technology in the twenty-first century has transformed the world in multiple, exciting and unanticipated ways. Facilitating the rapid flow of information, capital and services across the globe, it has dramatically revolutionised the way we work, communicate and interact with one another. More affordable travel, mobile communication devices, social media and online connectivity have enabled new patterns of movement and forms of social participation. In this digitally connected world, people move fluidly across online and offline spaces, blurring the boundaries of time and space and transforming notions of public and private domains (Gee and Hayes 2011, p. 523). The concept of space has become more embedded in people's imaginations, leading to new identifications, allegiances and relations (Warriner 2007, p.523). As technology continues to permeate all aspects of human life and transform the social order, it has impacted on language and identity in significant ways.

We create virtual identity as Internet users in digital societies. It is the key that opens the portal of websites, it is in two forms: the first is real names that indicate our real personalities that we deal with on the ground, and the second form is based on fake (borrowed) names that do not affect reality, and this form is preferred by the majority of users to websites via The Internet to remain anonymous.

In an increasingly digital society, personal data has become a new form of currency. The biggest challenge for political and business leaders is to establish the trust that enables that currency to keep flowing. "Digital identity "is the sum of all digitally available information about an individual [Deborah, 2015, P.56]. It is becoming increasingly complete and traceable, driven by the exponential growth of available data and the big data capabilities to process it.

Identity is constituted in and through language (Norton, 2013, p. 4) and we use language to articulate ideas and to represent ourselves and our social relations. Drawing on Weedon, Norton (ibid.) defines identity as 'the way a person understands his or her relationship to the world, how that relation is constructed across time and space and how the person understands possibilities for the future'. Because a person's sense of self and relation to the world continuously shifts, identity is dynamic, multiple and even contradictory. As the digital provides multiple spaces where language is used in different ways, learners are able to move across online and offline realities with greater fluidity and perform multiple identities.

The digital identity is the sum of the attributes, connotations and symbols that a person uses to define himself in the virtual space, so he interacts and communicates on the basis of it with others so that its content may not correspond to his true identity in social reality. The virtual self voluntarily supervises its upbringing by moving through spaces The digital, which is a field of presentation and the introduction and exchange of various values, meanings and connotations, is the product of different cultural patterns, which makes the virtual identity subject to special bets and immediate negotiation processes that may support their original connotations, delegate them or give them a different connotation depending on the subject's 
ability to support the basic frameworks and elements. The problem is for his local identity, and his ability to escape from the mechanisms of domination that he is exposed to in the virtual space, especially as the process of interaction took an immediate emotional character in which the critical contemplative mind may be absent in favor of the immediate intellect, which calls for us to direct attention to the importance of the presence of the dimension of my values and vision. Authentic civilization to achieve meaningful communication that is reflected in real practice. [Kulthum, 2016, p.7]

\section{Review of Literatures}

In our new concept of digital identity on the Internet, the concept of identity is more complex or ambiguous, as it increases the characteristics of the electronic personality in number, type and quality, and through its continuous and complex interaction in various technological forms. That this space has provided the human being with a large and wide framework that contains many sub-frameworks, there is the subjective frame of the personality and there is the frame of the group or the hypothetical society to which he belongs. There is also the natural cultural framework from which the hypothetical individual starts in addition to the new wider cosmic framework, from which the hypothetical individual can be freed Through it and launches with all its capabilities and digital representational energies, and each of these aforementioned frameworks has characteristics that define an identity for the hypothetical individual, as well as that any of these frameworks can be falsified and changed by the individual himself, or by an external penetration from the will of the individual concerned.

'Digital identity' information is intended to cover the broad set of information encompassed in the definition of identity, ie:

1. The collective aspect of the set of characteristics by which a thing is definitively recognizable or known.

2. The set of behavioral or personal characteristics by which an individual is recognizable as a member of a group.

3. The distinct personality of an individual regarded as a persisting entity; individuality.

4. Information, such as an identification number, used to establish or prove person's individuality. [Sylvia et al, 2008, p. 11]

A digital identity is defined as "the distinguishing character or personality of an individual. An identity consists of traits, attributes, and preferences upon which one may receive personalized services. Such services could exist online, on mobile devices at work, or in many other places". [Jean-Marc and Tewfiq, 2009, p. 270].

Techopedia.com explains Digital Identity, Like its human counterpart, a digital identity is comprised of characteristics, or data attributes, such as the following:

1. Username and password

2. Online search activities, like electronic transactions

3. Date of birth

4. Social security number

5. Medical history

6. Purchasing history or behavior

A digital identity is linked to one or more digital identifiers, like an email address, URL or domain name. Because identity theft is rampant on the Web, digital identity authentication and validation measures are critical to ensuring Web and network infrastructure security in the public and private sectors. 
At the same time, the volume of data that is available, collected and analysed is growing rapidly, thanks to ubiquitous connectivity, vast increases in processing power and the growth of new sources like social media, online transactions, in-product sensors and digital media. The ability to put this data to good use - not the uses consumers fear but ones that can benefit them - is growing, too.

Views on digital identity tend to take one of two extremes: Let organisations do what they need to in order to realise the economic potential of "Big Data," or create powerful safeguards to keep private information private. But digital identity can't be cast in such black-and-white terms. While consumers voice concern about the use of their data, their behaviours - and their responses to a survey conducted specifically for this report demonstrate that they are willing, even eager, to share information when they get an appropriate benefit in return. Indeed, as European Commissioner for Justice Viviane Reding remarked, "Personal data is in today's world the currency of the digital market. And like any currency it has to be stable and it has to be trustworthy. "This is a crucial point. Consumers will "spend" their personal data when the deals - and the conditions - are right. The biggest challenge for all stakeholders is how to establish a trusted flow of this data. [Bellman, et al, 2001, p. 7].

\section{Discussion}

\subsection{Digital Identity and Privacy Violation}

Identity in the modern era is increasingly dependent on the Internet, especially with regard to information, forums, social networking sites, games and the applications it provides. This has resulted in an increasing demand for privacy rights that protect the creation of a virtual identity without hindrance, especially with the increasing number of people who make up their identity on the Internet, and this would better protect the independent and unimpaired development of virtual identity in cyberspace, recognizing virtual identities as separate assets and allocating Virtual privacy rights provide an opportunity to organize cyberspace, in an innovative way.

"Digital Privacy" is a description of the protection of an individual's personal data, which is published and circulated through digital media. Personal data is represented in email, bank accounts, personal photos, information about work and residence and all data that we use in our interaction on the Internet while we use the computer, mobile phone or any of the means of digital communication on the Internet.

Due to the increasing interaction of individuals with the digital world, privacy has become threatened, and personal data has become a material that is either used commercially to carry out marketing advertising, or be monitored by government agencies, or expose it to theft and use it for purposes harmful to its owners. As preserving digital privacy is a recent issue, dealing with abuses that affect it by governments or any other parties need many directions on how to protect it through updating the relevant legal frameworks.

\subsection{Crimes of Violating the Privacy of Digital Identity}

It has become easy to obtain information stored on a computer connected to the Internet, and information can also be exchanged from one computer to another.

The confidentiality argument guaranteed by the automated data-processing system is no longer convincing, as instances of intrusion into the automated system have become an incoming issue and not impossible.

If we add to this the possibility of error in the operation of the machine, the difficulty of correcting the information, as well as the possibility of altering it in the first place to multiply 
the danger that threatens a person's private life due to the automated system for processing information. Personal data related to the private life of an individual or his family is often provided by the person himself or the bodies may reach it by one means or another, and the threat to prejudice to life may arise if it disclose this information without his consent, or it is published in one of the methods of publicity without his consent, whether this information is in the form of News, comment or photo. And be connected to the secrets of his own family or even if it was true.

Therefore, the digital world is filled with images of the violation of privacy and theft of digital identity, which are many and different. We will mention some of them:

1. Enter fake information.

2. Cyber intrusion on how to grow a virus on a computer CD.

3. Theft and forgery of private information.

4. Electronic infiltration of data and fraud.

The process of entering the information system is carried out by violating these ports and accessing the database, modifying it or adding false information with it in order to illegally benefit from that data.

Identity is an essential component of human subjectivity and a component of our experience as conscious and active players in the world. Therefore, it is not surprising that the approaches concerned with life in the networked society include statements about redirecting human experience in the matter of identity, coupled with the changes taking place in the human technical, economic and political system.

This is what Anthony Goddens refers to when he describes the contemporary situation as a "post-traditional system" where "the self becomes a flexible, reflexive project." The importance of the sources of meaning and traditional identity has vanished in contemporary capitalist societies, allowing people to construct their identity in a reflective manner, rather than accepting existing identities in a negative way. The questions in the above were, like "Who are we?" Exclusive competence of poets, philosophers and clerics. Now, individuals in contemporary societies live with the question of "Who am I?" in their daily "lifestyle choices". [Baren,2004, p.146]

The identity presence in the digital environment confronts a set of challenges that we can review as follows:

- From changing lifestyle to changing oneself: Identity on the Internet is becoming multiple, artificial and reviewable over and over again. Networked self-practices have a different, multiple, heterogeneous, and fragmented nature.

- Inability and fading of the body: Many of the technical features of networked media environments are compatible with identity, the first of which is the non-physical nature of communication networks that shrinks the geographical range to become a determining factor in identification, and the second, that network communication is not embodied, and does not require a common presence for routine interaction between people.

- Multiple Identities: In the virtual world, people choose, manipulate, distort or highlight their identities. Besides, people can choose more than one identity, and easily review their multiple identities, and ensure that their "self" is no longer a hostage of their history except as much as it is hostage to their name, body, or otherwise.

- Between anonymity and control: Those who search for the performance of alternative identities that have been assigned to them in the real world may succeed in continuing to assimilate those identities on the Internet platform. However, most people enter the virtual world with completed identities and are not seeking new identities. The same is true for focusing on anonymity in hypothetical transactions. It can blind on an important point of identity in the context of Internet-mediated communication. 
- A unique cyber entity: often begins your journey into cyberspace as an individual. In front of the computer screen. Where you can experience your uniqueness before building the feeling of others in the electronic world. While your computer screen acts as a window to your second home and you can simply connect to the cyber-space by logging in by entering your individual name online and your personal secret password.

Almost everyone spends their first moment in cyberspace in individual places

\section{Conclusion}

On the internet you almost always give away a lot of information about yourself: Unencrypted e-mails can be read by the administrators of the e-mail server, if the connection is not encrypted (no https), and also the internet service provider and other parties sniffing the traffic of that connection are able to know the contents. Furthermore, the same applies to any kind of traffic generated on the Internet (web-browsing, instant messaging, among others) In order not to give away too much personal information, e-mails can be encrypted and browsing of webpages as well as other online activities can be done traceless via anonymizers, or, in cases those are not trusted, by open source distributed anonymizers, so called mix nets.

More and more people are conducting their personal affairs online. Online shopping, social networking, job hunting and the ability to carry out 'official' functions, such as renewing car tax or contacting local councils and government departments online, are now an everyday part of life.

As long as digital technology penetrates into the folds of our lives, and as long as most of our usual activities are managed in a virtual space, then we are in one way or another subject to radical transformations that affect our selves and identities, our individuality, our unity, and our relationships, so that none of the aforementioned is as it was in the past, and since interaction interacts The key to cyber space is where you can build a new sense of self and control. The result of testing new senses is the "new feeling of being". This is the result of the effects of design technology and what is actually happening in virtual environments Communicative.

Digital identity has long been a part of our identity. It is no longer something we can or should protect ourselves from. But we should understand it in the same way that we have to follow in order to understand analogous behavior patterns. As difficult as that task is, we have no other choice but to face it 


\section{References}

Baren, D. 2004. The Network Society. Polity Press Ltd. UK. P. 146.

Bellman, S., E.J. Johnson, \& G.L. Lohse, 2001, "On site: to opt-in or opt-out?: it depends on the question", Communications of the ACM, 44(2): 25-27.

Deborah Gonzales, in Managing Online Risk: Apps, Mobile, and Social Media Security". 2015. P.56. Elsevier. UK.

Dr.Jean-Marc Seigneur, Dr.Tewfiq El Maliki, in Computer and Information Security Handbook, 2009. p. 270.

Edwards, J. (2009). Language and identity: An introduction. Cambridge: Cambridge University Press.

Gee, J.P. and Hayes, E.R. (2011). Language and learning in the digital age. Abingdon: Routledge.

Giddens, A. 1976. New Rules of Sociological Method: A Positive Critique of Interpretative Sociologies, London: Hutchinson.

https://www.techopedia.com/definition/23915/digital-identity.

Kulthum Peepmon: Cultural Contexts Directed for Digital Identity, In Light of the Challenges of Networked Society from Virtual Circulation to Realistic Practice, Additions Magazine, Issues 33-34, 2016, p.7

Norton, B. (2013). Identity and language learning: extending the conversation. 2nd edn. Bristol: Multilingual Matters.

Schwartz, S. J. (2001). The evolution of Eriksonian and neo-Eriksonian identity theory and research: A review and integration. Identity: An International Journal of Theory and Research, 1, 7-58.

Sylvia Khatcherian et al. 2008. Digital identity: principles on collection and use of information. Report of IBA Legal Practice Division Working Group. p: 11

Vignoles, V. L. (2011). Identity motives. In S. J. Schwartz, K. Luyckx, \& V. L. Vignoles (Eds.), Handbook of identity theory and research (pp. 403-432). New York: Springer.

Warriner, D.S. (2007). 'Transnational literacies: Immigration, language learning and identity', Linguistics and Education, 18(3): 201-214. 